\title{
Decreased Serum Triiodothyronine in Starving Rats is Due Primarily to Diminished Thyroidal Secretion of Thyroxine
}

\author{
W. B. Kinlaw, H. L. Schwartz, and J. H. Oppenheimer \\ Division of Endocrinology, Department of Medicine, University of Minnesota, Minneapolis, Minnesota 55455
}

\begin{abstract}
Although thyroxine $\left(\mathrm{T}_{4}\right) 5^{\prime}$-deiodinase activity is diminished in liver homogenates of starved rats, no information is available regarding the effect of starvation on net $T_{4}$ to triiodothyronine $\left(\mathrm{T}_{3}\right)$ conversion in the intact rat. It appeared important to clarify this relationship since rat liver homogenates are widely used as a model for the study of the factors responsible for reduced circulating $T_{3}$ in chronically ill and calorically deprived patients. In contrast to the expected selective decrease in circulating $T_{3}$ levels in calorically restricted humans due to diminished $T_{4}$ to $T_{3}$ conversion, $5 \mathrm{~d}$ of starvation of two groups of male Sprague-Dawley rats resulted, paradoxically, in a greater decrease in serum $T_{4}$ than in serum $T_{3}$ levels. Kinetic studies show that starvation is associated with no change in the metabolic clearance rate (MCR) of $\mathrm{T}_{3}$, a $20 \%$ increase in the MCR of $T_{4}, a 67 \%$ reduction in turnover rate of $T_{4}$, but only a 58\% reduction in the turnover rate of $T_{3}$. Moreover, in the first group of rats studied, direct chromatographic analysis of the isotopic composition of total body homogenates after the injection of ${ }^{125} \mathrm{I}-\mathrm{T}_{4}$ showed that $21.8 \%$ of $\mathrm{T}_{4}$ is converted to $T_{3}$ in control rats and $28.8 \%$ in starved rats, suggesting that virtually all extrathyroidal $T_{3}$ in starved and control rats is derived from the peripheral conversion of $T_{4}$, and that there is little or no direct thyroidal secretion of $T_{3}$. Our findings strongly point to a reduced thyroidal secretion of $T_{4}$ as the primary cause of the observed reduction in circulating $T_{3}$. Since the mechanisms leading to reduced levels of plasma $T_{3}$ differ in humans and rats, it may be important to reexamine the use of liver homogenate preparations as models for study of the pathogenesis of the "low $T_{3}$ syndrome" in humans.
\end{abstract}

\section{Introduction}

In man, the low concentration of serum triiodothyronine $\left(T_{3}\right)^{1}$ associated with starvation and catabolic disease results from diminished peripheral conversion of thyroxine $\left(T_{4}\right)$ to $T_{3}$. This conclusion is based primarily on the finding that, in starvation, the turnover of $T_{3}$ is more markedly reduced than the turnover of $T_{4}$, and that the bulk of circulating $T_{3}$ is derived from the

Address correspondence to Dr. Oppenheimer.

Received for publication 21 August 1984 and in revised form 14 November 1984

1. Abbreviations used in this paper: $\mathrm{CR}$, conversion ratio; ${ }^{125} \mathrm{I}-\mathrm{T}_{3},{ }^{125} \mathrm{I}-$ labeled $\mathrm{T}_{3} ;{ }^{125} \mathrm{I}-\mathrm{T}_{4},{ }^{125} \mathrm{I}$-labeled $\mathrm{T}_{4} ;{ }^{131} \mathrm{I}-\mathrm{T}_{3},{ }^{131} \mathrm{I}$-labeled $\mathrm{T}_{3}$; MCR, metabolic clearance rate; PR, production rate; PTU, propylthiouracil; $\mathrm{T}_{3}$, triiodothyronine; $\mathrm{T}_{4}$, thyroxine; $\mathrm{TSH}$, thyroid-stimulating hormone; $V_{\mathrm{d}}$, volume of distribution.

J. Clin. Invest.

(c) The American Society for Clinical Investigation, Inc.

$0021-9738 / 85 / 04 / 1238 / 04 \$ 1.00$

Volume 75, April 1985, 1238-1241 monodeiodination of $\mathrm{T}_{4}$ rather than direct thyroidal secretion $(1,2)$.

Experimental efforts to elucidate the biochemical basis and possible functional significance of the "low $T_{3}$ syndrome" have prompted the widespread use of animal models. The starving rat is most commonly used because in this model both the circulating level of $T_{3}$ and the in vitro conversion of $T_{4}$ to $T_{3}$ in liver homogenates are reduced (3-6). Several reports indicate, however, that the relative reduction of the plasma $T_{4}$ observed in the starved rat exceeds that of $T_{3}(3,7)$, precisely the opposite of the expected consequence of diminished fractional conversion. Moreover, the low thyroid-stimulating hormone (TSH) levels reported in this model $(8,9)$ further suggest that reduced thyroidal secretion of $\mathrm{T}_{4}$, rather than impaired monodeiodination, could fully account for the diminished circulating $T_{3}$. Nevertheless, we were unaware of any studies that attempt to quantitate the effects of starvation on the kinetics of iodothyronine metabolism in vivo. We therefore determined, in this study, the effects of starvation on $T_{4}$ and $T_{3}$ plasma turnover rates and assessed $T_{4}$ to $T_{3}$ conversion in vivo from an analysis of the isotopic composition of whole body homogenates.

\section{Methods}

Male Sprague-Dawley rats weighing 175-200 g were obtained from Bio-Lab, Inc. (White Bear Lake, MN) and housed individually. Control rats had free access to food (Wayne Lab-Blox, Allied Mills, Inc., Chicago, IL). The experimental groups in all cases were used for study after $96 \mathrm{~h}$ of complete starvation. Water was always freely available to both groups. ${ }^{125} \mathrm{I}$-labeled $\mathrm{T}_{4}\left({ }^{125} \mathrm{I}-\mathrm{T}_{4}\right)$ and $\mathrm{T}_{3}\left({ }^{125} \mathrm{I}-\mathrm{T}_{3}\right)$ were obtained from Abbott Laboratories, North Chicago, IL. ${ }^{131} \mathrm{I}$-labeled $\mathrm{T}_{3}\left({ }^{131} \mathrm{I}-\mathrm{T}_{3}\right)$ was prepared in the laboratory as previously described (10). All isotopic preparations were checked for purity by paper chromatography using the system of Bellabarba et al. (t-amyl alcohol/hexane/ammonia, 5:1: 6, vol/vol) (11). Contaminating ${ }^{125} \mathrm{I}_{-} \mathrm{T}_{3}$ in ${ }^{125} \mathrm{I}-\mathrm{T}_{4}$ preparations was found to be $<0.8 \%$ in all cases. Less than $1 \%{ }^{125} \mathrm{I}_{-} \mathrm{T}_{4}$ was observed in the radiolabeled $\mathrm{T}_{3}$.

The kinetics of $T_{3}$ and $T_{4}$ metabolism were studied in two separate experiments in which rats received intravenous injections of tracer doses $(<10 \mathrm{ng} / 100 \mathrm{~g}$ body $\mathrm{wt})$ of ${ }^{125} \mathrm{I}-\mathrm{T}_{3}$ or ${ }^{125} \mathrm{I}-\mathrm{T}_{4}$. Blood was sampled from the tail veins $10 \mathrm{~min}$ before injection and $5 \mathrm{~min}, 3,6,15$, and $24 \mathrm{~h}$ after injection. Residual hormone in plasma was separated from ${ }^{125}$ I-iodide by precipitation with TCA. We have shown that TCA precipitation yields values for $T_{3}$ that are not consistently different from those resulting from chromatographic techniques (12). Metabolic clearance rate (MCR), fractional removal rates, and volume of distribution $\left(V_{\mathrm{d}}\right)$ were calculated using noncompartmental methods. The interval from $t=0$ to $t=24 \mathrm{~h}$ was integrated with graphic displays of the data. The interval from $t=24 \mathrm{~h}$ to $t=\infty$ was calculated by use of equations previously defined (13). Plasma samples taken before injection of isotope were used for measurement of immunoassayable $\mathrm{T}_{\mathbf{4}}$, using a Quantitope kit (Kallestad Laboratories, Inc., Austin, TX). Unextracted plasma or serum was used for this assay, so we tested for possible changing specificity due to alterations in serum components resulting from experimental manipulation. Recovery of added $T_{4}(2.5-$ $22 \mu \mathrm{g} / \mathrm{dl}$ ) was measured in pools of serum of control and starved rats. 
Recovery was $103.8 \pm 6.0 \%$ and $101.4 \pm 2.9 \%$ in control and starved pools, respectively. $T_{3}$ was measured by the method of Surks et al. (14). Hormone production rates (PR) were estimated from the product of the MCR and the plasma hormone concentration.

The rate of conversion of $T_{4}$ to $T_{3}$ in the whole rat was measured as previously described (15) in rats from the group used for the first turnover studies. Doses of ${ }^{125} \mathrm{I}-\mathrm{T}_{4}(100 \mu \mathrm{Ci} / \mathrm{rat})$ were injected via the tail vein. $2 \mathrm{mg}$ of iodide were simultaneously injected intraperitoneally to prevent recycling of radioactive iodide. Rats were killed $48 \mathrm{~h}$ later. To correct for spurious deiodination during the analytical procedure other rats were similarly injected and killed within $2 \mathrm{~min}$. Intestinal contents and the urine in the bladder were removed. The entire carcass was then homogenized with added ice-cold water containing $10^{-4} \mathrm{M}$ propylthiouracil (PTU). Two 5-g aliquots of homogenate were extracted with absolute ethanol containing $10^{-4} \mathrm{M}$ PTU until $80-90 \%$ of the counts were removed. ${ }^{131} \mathrm{I}-\mathrm{T}_{3}$ was added to the extract to serve as a marker for $T_{3}$ during chromatographic isolation of the ${ }^{125} \mathrm{I}-\mathrm{T}_{3}$ derived from the injected ${ }^{125} \mathrm{I}-\mathrm{T}_{4}$ and to allow corrections for losses during the isolation procedure. Further, a constant ${ }^{125} \mathrm{I}_{-} \mathrm{T}_{3}$ to ${ }^{131} \mathrm{I}-\mathrm{T}_{3}$ ratio was used as a strict criterion of purity of the isolated ${ }^{125} \mathrm{I}-\mathrm{T}_{3}$. The extracts were concentrated in vacuo and applied to $3 \mathrm{MM}$ paper (Whatman Inc., Clifton, $\mathrm{NJ}$ ) together with unlabeled $T_{3}$ and $T_{4}$. The products were separated by chromatography in t-amyl alcohol/hexane/ammonia. The $T_{3}$ area was then visualized under ultraviolet light, eluted with methanol/ammonia (95:5), and rechromatographed. This procedure was repeated for a total of three runs. The final chromatogram was stained with diazotized sulfanilic acid (16) and the $T_{3}$ area cut into $0.5-\mathrm{cm}$ pieces. The ratio of ${ }^{125} \mathrm{I}-\mathrm{T}_{3}$ (from ${ }^{125} \mathrm{I}-\mathrm{T}_{4}$ ) to ${ }^{131} \mathrm{I}-\mathrm{T}_{3}$ was determined, with appropriate corrections for spillover from the ${ }^{131} I$ channel to the ${ }^{125} I$ channel as well as for recovery of the ${ }^{131}{ }^{1}-T_{3}$. Carcass content of ${ }^{125}$ I-iodide was estimated from chromatography of a small aliquot of the original extract. The percent of total ${ }^{125}$ I counts present in the carcass as $T_{3}$ was calculated from the equation (15):

$\left({ }^{125} \mathrm{I} /{ }^{131} \mathrm{I}\right) \times{ }^{131} \mathrm{I}-\mathrm{T}_{3} \times 100 /{ }^{125} \mathrm{I}$,

where ${ }^{125} \mathrm{I} /{ }^{131} \mathrm{I}$ is the corrected ratio of isotopes in the $T_{3}$ area of the chromatogram; ${ }^{131} \mathrm{I}-\mathrm{T}_{3}$, the known amount of counts added to the original extract; and ${ }^{125} \mathrm{I}$, the total counts of this isotope present in the carcass. The percent of ${ }^{125} \mathrm{I}_{-} \mathrm{T}_{4}$ remaining in the carcass was taken as the difference between the total ${ }^{125} \mathrm{I}$ radioactivity and the fraction of ${ }^{125} \mathrm{I}$-iodide and ${ }^{125} \mathrm{I}-\mathrm{T}_{3}$. The fractional turnover of $\mathrm{T}_{4}$ was estimated from the percent of $T_{4}$ and the residual radioactivity in a weighed aliquot of the carcass homogenate. The fractional turnover of $T_{3}$ was similarly measured in four separate rats killed $18 \mathrm{~h}$ after the intravenous injection of ${ }^{125} \mathrm{I}-\mathrm{T}_{3}$. The conversion ratio (CR) was calculated as follows (14):
$\mathrm{CR}=200\left(\mathrm{~T}_{3}{ }^{*} / \mathrm{T}_{4}{ }^{*}\right) /\left(\left[\lambda_{3} / \lambda_{4}\right]-1\right)$,

where the factor 200 is used to account for random deiodination in the $3^{\prime}$ and $5^{\prime}$ positions (15) and expression of the result as a percent; $\mathrm{T}_{3}{ }^{*} / \mathrm{T}_{4}{ }^{*}$ is the isotopic ratio in the carcass; and $\lambda_{3}$ and $\lambda_{4}$ are the fractional removal rates of the hormones.

\section{Results}

Starvation resulted in the reduction of serum $T_{4}$ in group I and group II rats to 21 and $32 \%$ of the basal levels, respectively (Table I). In both cases the decreases in circulating $\mathrm{T}_{3}$ were proportionally smaller, to 42 and $48 \%$ of the respective fed values. The MCR of $\mathrm{T}_{4}$ was increased in both groups by $20 \%$, whereas that of $T_{3}$ appeared unaffected. Despite the small increase in the MCR of $T_{4}$, the turnover of this hormone was markedly reduced, to 28 and $32 \%$ of control in the two starved groups. In each experiment, the reduction in $T_{4}$ turnover was proportionally greater than that for $T_{3}$. The latter was reduced only to 40 and $46 \%$ of control values in groups I and II, respectively. The disproportionate reduction of $T_{4}$ turnover rate is the opposite of the reduction expected from major impairment of fractional $T_{4}$ to $T_{3}$ conversion. Rather, the magnitude of the decrease in plasma $T_{4}$ levels (68 and 79\%) in the face of only a $20 \%$ increase in the MCR of $\mathrm{T}_{4}$ strongly suggested that the major cause of the hypothyroxinemia is reduced thyroidal secretion. Though it seemed unlikely, we could not entirely exclude the theoretical possibility that diminished fractional conversion of $T_{4}$ to $T_{3}$ was obscured by a relative increase in $T_{3}$ secretion.

To address this issue directly, we quantitated conversion of ${ }^{125} \mathrm{I}_{-} \mathrm{T}_{4}$ to ${ }^{125} \mathrm{I}-\mathrm{T}_{3}$ in a group of rats studied simultaneously with the first group of rats subjected to turnover studies (Table II). Normal rats exhibited a conversion ratio of $21.8 \pm 5.1 \%$ (mean \pm SD) that did not differ statistically from the ratio in starved animals of $28.8 \pm 14.3 \%$.

\section{Discussion}

Our finding that starvation in the rat results in a marked reduction in turnover of $T_{4}$ is consistent with previous reports of lowered levels of $T_{4}$ and TSH in starved rats $(8,9)$. Since the turnover rate of $T_{4}$ actually decreased more sharply in

Table I. Plasma Thyroid Hormone Kinetics in Two Groups of Starved Rats

\begin{tabular}{|c|c|c|c|c|}
\hline & \multicolumn{2}{|l|}{ Group I } & \multicolumn{2}{|l|}{ Group II } \\
\hline & Control & Starved & Control & Starved \\
\hline & $n=4$ & $n=5$ & $n=6$ & $n=6$ \\
\hline Plasma $\mathrm{T}_{4}(n g / m l)$ & $47 \pm 2 *$ & $10 \pm 6 \ddagger$ & $62 \pm 5$ & $20 \pm 5 \ddagger$ \\
\hline MCR $\mathrm{T}_{4}(\mathrm{ml} / 100 \mathrm{~g}$ body $w t / d)$ & $30 \pm 2$ & $36 \pm 4 \ddagger$ & $34.3 \pm 3.1$ & $41.0 \pm 8.2$ \\
\hline $\mathrm{PR} \mathrm{T}_{4}(n g / 100 \mathrm{~g}$ body $w t / d)$ & $1,400 \pm 11$ & $390 \pm 250 \ddagger$ & $2120 \pm 215$ & $804 \pm 164 \ddagger$ \\
\hline$\left(V_{\mathrm{d}}\right)_{\mathrm{r}_{4}}(m l / 100 \mathrm{~g}$ body $w t)$ & $25.8 \pm 1.3$ & $27.6 \pm 1.6$ & $24.7 \pm 4.1$ & $23.7 \pm 2.5$ \\
\hline Plasma $\mathrm{T}_{3}(n g / m l)$ & $0.73 \pm 0.09$ & $0.31 \pm 0.08 \ddagger$ & $0.54 \pm 0.05$ & $0.26 \pm 0.05 \ddagger$ \\
\hline $\operatorname{MCR} \mathrm{T}_{3}(\mathrm{ml} / 100 \mathrm{~g}$ body $w t / d)$ & $315 \pm 78$ & $314 \pm 89$ & $366 \pm 53$ & $335 \pm 41$ \\
\hline $\mathrm{PR} \mathrm{T}_{3}(n g / 100$ body $w t / d)$ & $233 \pm 88$ & $93 \pm 20 \ddagger$ & $196 \pm 34$ & $89 \pm 25 \ddagger$ \\
\hline$\lambda 3(h)$ & $0.085 \pm 0.041$ & $0.104 \pm 0.018$ & $0.102 \pm 0.077$ & $0.093 \pm 0.028$ \\
\hline$\left(V_{\mathrm{d}}\right)_{\mathrm{r}_{3}}(m l / 100 \mathrm{~g}$ body $w t)$ & $150.1 \pm 107.2$ & $133.1 \pm 50.5$ & $194.4 \pm 68.8$ & $162.6 \pm 38.4$ \\
\hline
\end{tabular}

$\lambda 3$ and $\lambda 4$ indicate the fractional removal rates of $T_{3}$ and $T_{4}$ as determined by noncompartmental analysis. $*$ Mean \pm SD. $\ddagger$ Different from control; $P<0.05$ by $t$ test. 
Table II. $T_{4}$ to $T_{3}$ Conversion in Whole Rats

\begin{tabular}{lcc}
\hline & Control & Starved \\
\hline & $n=4$ & \\
$\mathrm{CR}(\%)$ & $21.8 \pm 5.1^{*}$ & $28.8 \pm 14.3(n=4)$ \\
$\lambda 3(/ h)$ & $0.096 \pm 0.014$ & $0.110 \pm 0.016(n=5)$ \\
$\lambda 4(/ h)$ & $0.046 \pm 0.003$ & $0.045 \pm 0.008(n=4)$ \\
\hline
\end{tabular}

$\lambda 3$ and $\lambda 4$ are the fractional removal rates of $T_{3}$ and $T_{4}$ determined from the residual radioactivity in the carcass $18 \mathrm{~h}$ and $48 \mathrm{~h}$, respectively, after intravenous injection of ${ }^{125} \mathrm{I}_{-} \mathrm{T}_{3}$ or ${ }^{125} \mathrm{I}-\mathrm{T}_{4}$.

* Mean \pm SD.

both groups of rats studied than did the turnover rate of $T_{3}$, there appears to be no need to postulate diminished overall conversion of $T_{4}$ to $T_{3}$ to account for the lowered levels of $T_{3}$. The possibility that diminished conversion of $T_{4}$ to $T_{3}$ by peripheral tissues could be offset by a concomitant increase in the relative secretion of $T_{3}$ is highly unlikely since increased rather than decreased levels of TSH are generally believed to preferentially stimulate thyroidal $T_{3}$ secretion (17). Nevertheless, in conjunction with the study of the first group of rats, we attempted to measure the fractional conversion of isotopic $T_{4}$ to $T_{3}$ by chromatographic analysis of total body homogenates, as previously described from our laboratory (15). The results of these experiments provided no evidence of a decrease in the conversion ratio.

The mean conversion ratio in normal rats, $21.8 \%$, is in general agreement with our previously published value of $17 \%$ (15) and the $22 \%$ value recently reported by Silva et al. (18), and it lies within the theoretical range of $14-24 \%$, predicted by DiStefano et al. (19). Higher values (33 and 27\%), however, have been reported by Boonnamsiri et al. (20) and Zimmerman et al. (21), respectively. If the value $21.8 \%$ is applied to the measured $\mathrm{T}_{4}$ turnover rate in the group $\mathrm{I}$ rats, the corresponding $\mathrm{PR}$ of $\mathrm{T}_{3}$ yields a value $110 \%$ resulting from direct measurements. Similarly, if the value $28 \%$ is applied to the PR in the starved rats of group $I$, the PR of $T_{3}$ from $T_{4}$ is $101 \%$ the total $T_{3}$ turnover. These findings suggest, therefore, that essentially all of the extrathyroidal $T_{3}$ in the rat is produced by peripheral conversion from thyroxine, a conclusion differing markedly from our 1971 estimate (15) that only $20 \%$ of $T_{3}$ in the rat is produced by extrathyroidal conversion. However, our earlier calculations were based on borrowed literature values for $T_{3}$ and $T_{4}$ obtained by isotopic equilibration studies performed in the preradioimmunoassay era as well as on an MCR of $T_{4}$ that was considerably less than those measured in the present experiments. When, however, the conversion ratios obtained with group I rats were used in conjunction with the turnover ratios of group II rats, the calculated $T_{3} P R$ was approximately twice the PR observed by direct measurement. An examination of the data in Table $I$ indicates that the higher PR of $T_{4}$ in the second group of rats was largely due to a higher circulating $T_{4}$. We have been impressed by the substantial variation in the level of $T_{4}$ reported in normal rats, with recent reports as low as $29 \mathrm{ng} / \mathrm{ml} \mathrm{(19)} \mathrm{and} \mathrm{as} \mathrm{high} \mathrm{as} 70 \mathrm{ng} / \mathrm{ml}(22)$. To verify the validity of our methods, we carefully checked recovery of increasing concentrations of $\mathrm{T}_{4}$ added to pooled sera samples from fed and starved euthyroid rats and fed hypothyroid rats, and with each group, we obtained nearly $100 \%$ recovery, a finding that minimizes the possibility of a systematic analytic error. Moreover, we measured plasma $T_{4}$ in groups of rats from different suppliers. Individual groups ranged from $44 \pm 8$ (mean $\pm \mathrm{SD}, 6 /$ group) to $61 \pm 5 \mathrm{ng} / \mathrm{ml}$, measurements which approximate those of our two groups of experimental rats. We therefore believe that the variation in $\mathrm{T}_{4}$ levels is not spurious but represents the effect of as yet undefined genetic, environmental, or dietary factors. Consequently, we believe that it is likely that the conversion ratio of group II rats was lower than the value determined for group I rats. Thus, if one assumes no thyroidal $T_{3}$ secretion in these rats, one can calculate a maximal conversion ratio of $11 \%$ in the control and $13.2 \%$ in the starved group II rats, suggesting the operation of an autoregulatory system similar to that proposed by Lum et al. in humans (23). With increased concentrations of circulating $T_{4}$, decreased fractional conversion of $T_{4}$ to $T_{3}$ would occur. We did not make any effort to test this hypothesis because of the difficulty in determining the fractional conversion of $T_{4}$ to $T_{3}$ : multiple steps in the procedure, each with an inherent experimental error, lead to relatively imprecise net results. An inordinate number of rats exhibiting different basal $T_{4}$ levels would be required to establish valid distinctions in conversion rates.

Regardless of these considerations, it is clear that in the rat, in contrast to the results in humans, starvation consistently produced a greater reduction in $T_{4}$ than in $T_{3}$ turnover. Direct measurement of the conversion ratio by the isotopic technique provided no evidence for net reduction in peripheral $T_{4}$ to $T_{3}$ conversion. These results point to a reduction in thyroidal $T_{4}$ secretion as the major cause of the low $T_{3}$ levels in starved rats.

Our failure to infer an overall decrease in $T_{4}$ monodeiodination contrasts with many reports of a $40-50 \%$ reduction in the rate of $T_{4}$ to $T_{3}$ conversion in liver homogenates from starving rats (3-6). Unfortunately, there are no firm data that allow a quantitative estimate of the contribution of hepatic deiodination to the circulating pool of $\mathrm{T}_{3}$ either in the fed or starved rat. DiStefano et al. (19) have estimated that $\sim 50 \%$ of the $T_{3}$ generated in the normal rat is derived from tissues that equilibrate rapidly with $T_{4}$, namely liver and kidney, whereas the remaining $T_{3}$ appears to be derived from more slowly equilibrating tissues such as muscle and brain. It is possible that the contribution of the liver to total $\mathrm{T}_{4}$ monodeiodination is sufficiently small to obscure reduction in overall hepatic monodeiodination in the intact rat. Hypothetically, reduction in the rate of hepatic monodeiodination could be offset by augmented deiodination in other tissues. Larsen et al. (24) have shown that monodeiodination may proceed by separate enzymatic mechanisms in individual tissues and may respond in a differential manner to agents such as PTU. Moreover, Kaplan and Yaskoski (25) have shown that starvation causes a $60 \%$ increase in the rate of deiodination of hypothalamic tissue. It is possible, therefore, to postulate that increased deiodination occurs in nonhepatic tissues in starved rats. Alternatively, monodeiodination, as measured under in vitro conditions, may fail to accurately reflect the changes that occur in vivo. Under any circumstances it may be premature to assume that the biochemical mechanisms responsible for diminished monodeiodination in liver homogenates from starved rats can serve as a valid model for the pathogenesis of the low $\mathrm{T}_{3}$ syndrome in humans. 


\section{Acknowledgments}

Dr. Oppenheimer was supported by National Institutes of Health grant AM 19812 and by National Research Service training grant award AM 07203. Dr. Kinlaw was supported by National Research Service award AM 07110.

\section{References}

1. Vagenakis, A. G., G. I. Portnay, J. T. O'Brien, M. Rudolph, A. Arky, S. H. Ingbar, and L. E. Braverman. 1977. Effect of starvation on the production and metabolism of thyroxine and triiodothyronine in euthyroid obese patients. J. Clin. Endocrinol. Metab. 45:1305-1309.

2. Suda, A. K., C. S. Pittman, T. Shimizu, and J. B. Chambers. 1978. The production and metabolism of 3,5,3'-triiodothyronine and 3,3',5'-triiodothyronine in normal and fasting subjects. J. Clin. Endocrinol. Metab. 47:1311-1319.

3. Harris, A. R., C. S. Fang, A. G. Vagenakis, and L. E. Braverman. 1978. Effect of starvation, nutrient replacement, and hypothyroidism on in vitro hepatic $\mathrm{T}_{4}$ to $\mathrm{T}_{3}$ conversion in the rat. Metab. Clin. Exp. 27:1680-1690.

4. Kaplan, M. M., and R. D. Utiger. 1978. Iodothyronine metabolism in rat liver homogenates. J. Clin. Invest. 61:459-471.

5. Balsam, A., and S. H. Ingbar. 1978. The influence of fasting, diabetes, and several pharmacological agents on the pathways of thyroxine metabolism in rat liver. J. Clin. Invest. 62:415-424.

6. Chopra, I. J. 1980. Alterations in monodeiodination of iodothyronines in the fasting rat: effects of reduced nonprotein sulfhydryl groups and hypothyroidism. Metab. Clin. Exp. 29:161-167.

7. Oppenheimer, J. H., and H. L. Schwartz. 1980. Factors determining the level of activity of 3,5,3'-triiodothyronine-responsive hepatic enzymes in the starved rat. Endocrinology. 107:1460-1468.

8. Campbell, G. A., M. Kurez, S. Marshall, and J. Meites. 1977. Effects of starvation in rats on serum levels of follicle stimulating hormone, luteinizing hormone, thyrotropin, growth hormone and prolactin. Endocrinology. 100:580-587.

9. Harris, A. R. C., S. L. Fang, F. Azizi, L. Lipworth, A. G. Vagenakis, and L. E. Braverman. 1978. Effect of starvation in hypothalamic-pituitary-thyroid function in the rat. Metab. Clin. Exp. 27 1074-1083.

10. Surks, M. I., and H. C. Shapiro. 1969. Preparation of high specific activity nonphenolic-ring ${ }^{125} \mathrm{I}$ and ${ }^{14} \mathrm{C}$-labeled thyroxine. $J$. Clin. Endocrinol. Metab. 29:1263-1265.

11. Bellabarba, D., R. Peterson, and K. Sterling. 1968. An improved method for chromatography of iodothyronines. J. Clin. Endocrinol. Metab. 28:305-307.

12. Schwartz, H. L., D. Trence, J. H. Oppenheimer, N. S. Jiang, and D. B. Jump. 1983. Distribution and metabolism of L- and Dtriiodothyronine $\left(T_{3}\right)$ in the rat: preferential accumulation of L-T $T_{3}$ by hepatic and cardiac nuclei as a probable explanation of the differential biologic potency of $T_{3}$ enantiomers. Endocrinology. 113:1236-1243.
13. Oppenheimer, J. H., H. L. Schwartz, and M. I. Surks. 1975. Determination of common parameters of iodothyronine metabolism and distribution in man by noncompartmental analysis. J. Clin. Endocrinol. Metab. 41:319-324.

14. Surks, M. I., A. R. Schadlow, and J. H. Oppenheimer. 1972. A new radioimmunoassay for plasma L-triiodothyronine: measurements in thyroid disease and in patients maintained on hormonal replacement. J. Clin. Invest. 51:3104-3113.

15. Schwartz, H. L., M. I. Surks, and J. H. Oppenheimer. 1971. Quantitation of extrathyroidal conversion of L-thyroxine to 3,5,3'triiodo-L-thyronine in the rat. J. Clin. Invest. 50:1124-1130.

16. Pitt-Rivers, R., and H. L. Schwartz. 1969. Iodoamino acids and related compounds. In Chromatographic and Electrophoretic Techniques. I. Smith, editor. William Heineman Ltd., London. Vol. I. Third ed.

17. Inoue, K., Y. Grimm, and M. A. Greer. 1967. Quantitative studies on iodinated components secreted by the rat thyroid gland as determined by in situ perfusion. Endocrinology. 81:946-966.

18. Silva, J. E., M. B. Gordon, F. R. Crantz, J. L. Leonard, and P. R. Larsen. 1984. Qualitative and quantitative differences in the pathways of extrathyroidal triiodothyronine generation between euthyroid and hypothyroid rats. J. Clin. Invest. 73:898-907.

19. DiStefano, J. J., T. K. Malone, and M. Jang. 1982. Comprehensive kinetics of thyroxine distribution and metabolism in blood and tissue pools of the rat from only six blood samples: dominance of large, slowly exchanging tissue pools. Endocrinology. 111:108-117.

20. Boonnamsiri, V., J. C. Kermode, and B. D. Thompson. 1979. Prolonged intravenous infusion of labeled iodocompounds in the rat: $\left[{ }^{125} \mathrm{I}\right]$ thyroxine and $\left[{ }^{125} \mathrm{I}\right]$ tri-iodothyronine metabolism and extrathyroidal conversion of thyroxine to tri-iodothyronine. J. Endocrinol. 82:235241.

21. Zimmerman, C. J., M. Izumi, and P. R. Larsen. 1978. Isolation of labeled triiodothyronine from serum using affinity chromatography: application to the estimation of the peripheral $T_{4}$ to $T_{3}$ conversion in rats. Metab. Clin. Exp. 27:303-313.

22. Senga, O., C. S. Pittman, R. H. Lindsay, J. B. Chambers, and J. B. Hill. 1982. Comparison of peripheral thyroid hormone metabolism in normal rats and in rats receiving prolonged glucagon infusion. Endocrinology. 110:2011-2017.

23. Lum, S. M. C., J. T. Nicoloff, C. A. Spencer, and E. M. Kaptein. 1984. Peripheral tissue mechanism for maintenance of serum triiodothyronine values in a thyroxine-deficient state in man. J. Clin. Invest. 73:570-575.

24. Larsen, P. R., J. E. Silva, and M. M. Kaplan. 1981. Relationships between circulating and intracellular thyroid hormones: physiological and clinical implications. Endocr. Rev. 2:87-102.

25. Kaplan, M. M., and K. A. Yaskoski. 1982. Effects of congenital hypothyroidism and partial and complete food deprivation on phenolic and tyrosyl ring iodothyronine deiodination in rat brain. Endocrinology. 110:761-767. 